\title{
Dermoscopy of notalgia paresthetica
}

\author{
Subrata Malakar ${ }^{1}$, Purva Mehta $^{2}$, Surit Malakar ${ }^{3}$
}

\author{
${ }^{1}$ Medical Director, Rita Skin Foundation, Kolkata, India, ${ }^{2}$ Consultant Dermatologist, Rita Skin Foundation, Kolkata, India, \\ ${ }^{3}$ Consultant Dermatologist, Rita Skin Foundation, Kolkata, India
}

Corresponding author: Dr. Purva Mehta, E-mail: purvamehta86@gmail.com

Sir,

A middle aged female complained of certain sensations on the back in the subscapular region. On clinical examination, there was a circumscribed, hyperpigmented patch. A provisional diagnosis of notalgia paresthetica was made (Fig. 1). Dermoscopy was performed using a Dermlite DL3N at $10 \mathrm{x}$ magnification under polarised light.

Dermoscopy of this patch revealed alternating patches of hyperpigmentation and hypopigmentation (Fig. 2a). The hyperpigmented patches were brown to slate gray in colour and were present in various forms. They were arranged in an irregular net like pattern. In some areas the pigmentation was scattered with various patterns around a central hub which was either hypopigmented or hyperpigmented. Shiny white streaks were observed within the hypopigmented patches (Fig. 2b).

Notalgia paresthetica occurs due to nerve root entrapment of T2-T6 rami causing paresthesia resulting in chronic itching and friction. This friction leads to degeneration of keratinocytes and deposition of amyloid fibrils in cases of notalgia paresthetica. Amyloid fibrils are abnormally polymerised cytokertain derived material. These fibrils are birefringent and under polarised dermoscopy appear as shiny white

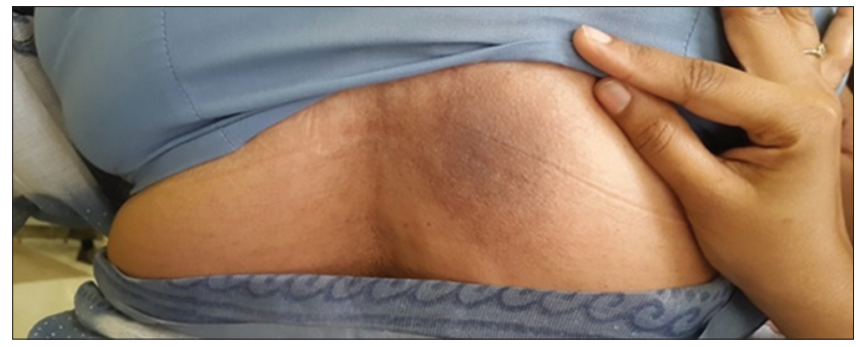

Figure 1: A case of notalgia paresthetica in a middle aged patient. streaks [1]. Thus, shiny white streaks in notalgia paresthetica correspond histologically to amyloid fibrils [2]. Hyperpigmentation of various patterns seen dermoscopically corresponds to either basal pigmentation of the epidermis or melanophages with pigment incontinence in the dermis.

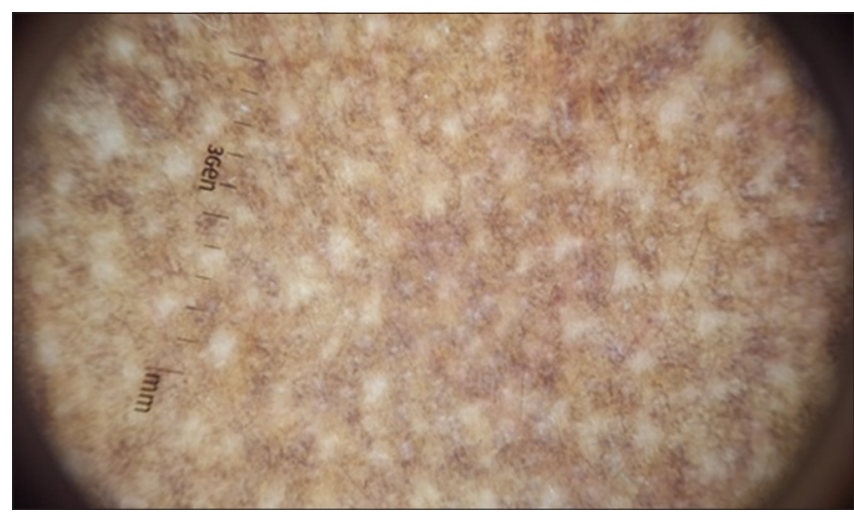

Figure 2a: Dermoscopic overview shows alternate hypopigmented and hyperpigmented patches throughout the lesion.

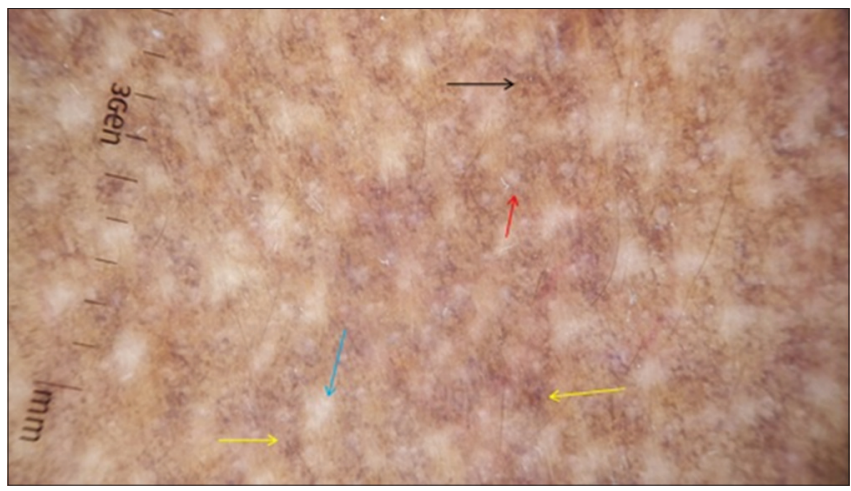

Figure 2b: Hyperpigmented patches are brown or slate gray in color. The pigment pattern may take the formation of irregular nets (black arrow), may have central hypopigmented hub (red arrow) or hyperpigmented hub (yellow arrow) surrounded by pigment configurations of different shapes and patterns. Shiny white streaks are also seen (blue arrow). 
www.odermatol.com

Due to its presentation, notalgia paresthetica may mimic macular amyloidosis not only clinically but also dermoscopically. However, shiny white streaks are absent in macular amyloidosis on dermoscopy providing a vital dermoscopic clue in differentiating the two conditions.

\section{Consent}

The examination of the patient was conducted according to the Declaration of Helsinki principles.

\section{REFERENCES}

1. Arnold S, Bowling J. 'Shiny white streaks' in lichen amyloidosis: A clue to diagnosis. Australas J Dermatol. 2012;53:272-3.

2. Shin J, Kim YC. Neuropathic Itch of the Back: A Case of Notalgia Paresthetica. Ann Dermatol. 2014;26:392-4.

Copyright by Subrata Malakar, et al. This is an open access article distributed under the terms of the Creative Commons Attribution License, which permits unrestricted use, distribution, and reproduction in any medium, provided the original author and source are credited.

Source of Support: Nil, Conflict of Interest: None declared. 